\title{
Introduction to topical collection on perspectivism in science: metaphysical and epistemological reflections
}

\author{
Michela Massimi $^{1}$ D
}

Received: 19 February 2021 / Accepted: 12 March 2021 / Published online: 17 April 2021

(c) Springer Nature B.V. 2021

It is a great pleasure to announce this Topical Collection (TC) on the theme of perspectivism in science, which has been at the centre of renewed interest and attention in recent years. When almost two years ago, I approached the Editors of the European Journal for the Philosophy of Science, Phyllis Illari and Federica Russo, with a proposal for a Topical Collection, I did not envisage the level of interest and the wonderful diversity of topics and themes in the papers that we were going to receive. I am very grateful to Phyllis and Federica for enthusiastically sharing the vision for this collection and for supporting it from beginning to end, often in demanding circumstances due to the COVID-19 pandemic. Very many thanks also to the EJPS Associate Editors for their constructive comments and advice along the way and to all the anonymous reviewers for making this TC possible.

This topical collection was an invitation to offer a better understanding of the philosophical view called "perspectivism" and its relevance to science by exploring a variety of metaphysical and epistemological issues arising from perspectivism in science. The papers here collected deliver on this two-fold goal. I will not try to summarise each of them, but suffice to say that they map onto three broad interrelated themes, which I shall call scientific practice, normativity, and history.

Scientific practice Perspectivism is-in broad terms-the philosophical view that stresses how scientific knowledge is historically and culturally situated, the product of a plurality of scientific perspectives. The latter are usually understood in the literature as families of scientific models, or, more in general, distinctive disciplinary approaches and methodologies. Several papers in this TC (i.e. Bschir, Boon,

This article belongs to the Topical Collection: Perspectivism in science: metaphysical and epistemological reflections

\section{Guest Editor: Michela Massimi}

Michela Massimi

michela.massimi@ed.ac.uk

1 School of Philosophy, Psychology and Language Sciences, The University of Edinburgh,

Dugald Stewart Building, 3 Charles Street, Edinburgh EH8 9AD, UK 
Potters, Lee \& Dewhurst, Keyser \& Howland, Veit \& Browning, Fellowes) speak to this theme by offering a wealth of case studies showing how a plurality of scientific perspectives is often needed for advancing knowledge production in relevant areas of inquiry.

Normativity But perspectivism is not just meant to be descriptive of scientific practice. Several papers in this collection speak to what might be called a normative dimension in perspectivism. Perspectivism is also an invitation to reflect on how one ought to think about questions concerning scientific representation, objectivity, realism, reference, mechanism and measurement, among others. Papers by Ruyant, Evans, Keyser \& Howland, Hoefer \& Martí, Lee \& Dewhurst, Baker and Potters all contribute to this further theme.

History Although none of these papers as such is historical, a few of them delve into the philosophical genealogy of perspectivism, old and new that it might be. For example, Sanjuán's paper looks at the neo-Kantian roots of perspectivism and connections with Reichenbach and more recently Friedman's Kantianism, while Berghofer's paper draws attention to the connection with the phenomenological tradition. Many other of these papers (e.g. Baker, Boon, Keyser \& Howland, Evans) engage with the more recent literature of Giere, van Fraassen, and Price, among others.

I thank all the authors for their contributions and patience in dealing with sometimes long editorial times due to COVID pandemic. And I thank the European Research Council (ERC) under the European Union's Horizon 2020 research and innovation program (grant agreement European Consolidator Grant H2020-ERC2014-CoG 647272 "Perspectival Realism: Science, Knowledge, and Truth from a Human Vantage Point"), for supporting my research as Guest Editor of this Topical Collection.

Publisher's Note Springer Nature remains neutral with regard to jurisdictional claims in published maps and institutional affiliations. 